\title{
Sequencing of bovine herpesvirus 4 v.test strain reveals important genome features
}

\author{
Leonor Palmeira, Bénédicte Machiels, Céline Lété, Alain Vanderplasschen and Laurent Gillet
}

\begin{abstract}
Background: Bovine herpesvirus 4 (BoHV-4) is a useful model for the human pathogenic gammaherpesviruses Epstein-Barr virus and Kaposi's Sarcoma-associated Herpesvirus. Although genome manipulations of this virus have been greatly facilitated by the cloning of the BoHV-4 V.test strain as a Bacterial Artificial Chromosome (BAC), the lack of a complete genome sequence for this strain limits its experimental use.
\end{abstract}

Methods: In this study, we have determined the complete sequence of BoHV-4 V.test strain by a pyrosequencing approach.

Results: The long unique coding region (LUR) consists of 108,241 bp encoding at least 79 open reading frames and is flanked by several polyrepetitive DNA units (prDNA). As previously suggested, we showed that the prDNA unit located at the left prDNA-LUR junction (prDNA-G) differs from the other prDNA units (prDNA-inner). Namely, the prDNA-G unit lacks the conserved pac-2 cleavage and packaging signal in its right terminal region. Based on the mechanisms of cleavage and packaging of herpesvirus genomes, this feature implies that only genomes bearing left and right end prDNA units are encapsulated into virions.

Conclusions: In this study, we have determined the complete genome sequence of the BAC-cloned BoHV-4 V.test strain and identified genome organization features that could be important in other herpesviruses.

\section{Background}

Gammaherpesviruses are archetypal persistent viruses which are ubiquitous in both human and animal populations. The human gammaherpesviruses, Epstein-Barr virus (EBV) and Kaposi's Sarcoma-associated Herpesvirus (KSHV), infect respectively some 90\% [1] and 30\% [2] of human populations and cause several cancers $[2,3]$. Although much effort has been invested on these viruses, studies of EBV or KSHV are difficult to perform directly because these viruses show limited lytic growth in vitro and have no well-established in vivo infection model. Related animal gammaherpesviruses are therefore an important source of information.

Bovine herpesvirus 4 (BoHV-4) belongs to the Gammaherpesvirinae subfamily, and to the Rhadinovirus genus [4]. Similarly to its human counterparts, BoHV-4 was found to be widespread in all bovine populations and to persist in the vast majority of individuals as a lifelong, asymptomatic infection [5]. However, in some

\footnotetext{
*Correspondence: I.gillet@ulg.ac.be Immunology-Vaccinology (B43b), Department of Infectious and Parasitic Diseases (B43b), Faculty of Veterinary Medicine, University of Liège, B-4000 Liège, Belgium
}

(C) 2011 Palmeira et al; licensee BioMed Central Ltd. This is an Open Access article distributed under the terms of the Creative Commons Attribution License (http://creativecommons.org/licenses/by/2.0), which permits unrestricted use, distribution, and reproduction in any medium, provided the original work is properly cited. circumstances, BoHV-4 has been associated with various clinical symptoms such as skin lesions, respiratory diseases, metritis, malignant catarrhal fever or tumors [5].

The virus was first isolated in Europe by Bartha et al. from calves with respiratory diseases [6] and later in North America by Mohanty et al. [7]. Besides cattle, BoHV-4 has also been detected in a variety of ruminants. In particular, BoHV-4 seems to be highly prevalent among wild African buffalo (Syncerus caffer) which could be considered as the natural reservoir of the virus [8-10]. Overall, more than 40 BoHV-4 strains have been isolated across the world. These strains can be classified in three groups: the European strains (or Movar 33/63like strains), the American strains (or DN 599-like strains) and the African buffalo strains [9].

It is estimated that the taurine and buffalo strains diverged around 730,000 years ago [9] and that the European and North American clades diverged around 260,000 years ago [9]. The genome of the BoHV-4 66-p347 North American strain has entirely been sequenced [11]. However, the BAC-cloned reference strain V.test $[12,13]$ belongs to the European clade $[9,14]$. Previous studies suggested that the BoHV-4 V-test strain contains 
regions of high dissimilarity compared to the BoHV-4 66p-347 strain. Indeed, the nucleotide identity between the two strains has been previously measured to be as low as $88 \%$ on the BORFB2 region [11]. However, the lack of a complete genomic sequence for the V.test strain prevents from drawing a general view concerning this divergence level. Therefore, the low quality of the genomic information hampers the use of the BAC-cloned BoHV-4 V.test strain as a good model for studying gammaherpesvirus biology. In this study, we have determined the genomic sequence of the BoHV-4 V.test strain and analyzed its overall differences with the available sequence of the BoHV-4 66-p-347 strain $[11,15]$. The results obtained highlighted important differences between BoHV-4 66-p347 and V.test strains. Moreover complete sequencing of the BoHV-4 V.test strain also revealed genome features potentially important in other herpesviruses.

\section{Methods}

BAC sequencing

BAC DNA was purified using Qiagen large-construct kit as described by the manufacturer. The complete BAC cloned viral genome of BoHV-4 V.test strain was determined by pyrosequencing using the 454 GS FLX Titanium (Roche) high-throughput sequencer and resulted in 48,967 reads of an average read length of 265 nucleotides and a total of $12,997,275$ bases. A targeted ABI-Sanger sequencing of fragments of the prDNA region was also conducted using the primers listed in Table 1 . The raw 454 data has been deposited in the NCBI Sequence Read Archive (SRA) database with accession number SRA037246.

\section{BoHV-4 genome LUR assembly}

The reads were de novo assembled with gsAssembler (Roche), where the E. coli genome was used as a contaminant to filter out cellular reads [16]. The filtering removed 1,167 contaminant cellular reads. The de novo assembly yielded 11 contigs which were subsequently BLASTed against 66-p-347's long unique region (LUR) and polyrepetitive DNA (prDNA) -accession numbers NC_002665 and AF092919- to define their relative positions [17]. Contigs were assembled into a large scaffold using two previously published V.test sequences (accession numbers Z46380 and Z46385 [18]) overlapping contig borders. A careful comparison of the bordering contigs with the previously sequenced fragments showed a high percent identity (>99.99\%). After verification of the quality of the assembly, the BAC sequence was removed and the genome sequence was annotated as detailed hereunder.

\section{BoHV-4 genome prDNA assembly}

The prDNA was determined by a hybrid 454/ABI-Sanger strategy where $17 \mathrm{ABI}$-Sanger fragments of prDNA were de novo assembled with the 454 reads. Briefly, in order to correctly assemble the prDNA and to disentangle different prDNA units, this second de novo assembly was optimized for highly repetitive segments using MIRA [19]. 454 reads and quality information were extracted from the raw .sff file with 'sff_extract'. The base-calling and quality-calling for Sanger sequences were inferred from the ab1 raw chromatogram files using 'phred' $[20,21]$ and the sequences were qualitytrimmed using 'lucy' [22]. MIRA assembler ( $\mathrm{v}$ 3.2.0) was used to build an assembly of the V.test genome with the following flags and options: "-job = denovo, genome, accurate, sanger, 454 -highlyrepetitive -AS:klrs = no 454_SETTINGS -AS:urdcm = 1.1: ardml = 100". This assembly yielded a very large contig containing a complete prDNA unit, and a second contig containing an incomplete unit bearing the prDNA/prDNA junction. The complete prDNA unit was extracted from the first contig and identified as being the last prDNA unit before the LUR junction and noted prDNA-G following Bublot et al. [14]. By analysing the contig bearing the prDNA/prDNA junction in GAP4 [23], we determined a 518 bp fragment of the prDNA-inner unit (as named by Bublot et al. [14]) bordered on the left by lower read qualities and coverage, and on the right by the beginning of a new prDNA unit. This end was joined to the beginning $(2,089 \mathrm{bp})$ of the prDNA-G unit in order to obtain a complete prDNA-inner unit $(2,607 \mathrm{bp})$. We verified that this complete unit was compatible with previously published information [14].

\section{BoHV-4 genome annotation}

All Open Reading Frames (ORFs) from all 6 frames were retrieved from the complete genomic sequence and matched against the Conserved Domain Database [24] using the position-specific scoring matrices (PSSM) based Reverse PSI-BLAST [25]. For all ORFs sharing the same STOP and containing a PSSM match, the smallest ORF containing the largest PSSM match was retained. 59 ORFs were thus considered evolutionarily conserved and were annotated with the corresponding matching conserved domains. Out of the 79 CDS from the previously published 66-p-347 strain, all 59 ORFs matched previously annotated 66-p-347 ORFs. The 20 remaining CDS were added by similarity to this strain and were annotated as such. Repeat segments and special features were annotated according to 66-p-347 if they were present in V.test. The complete genome sequence containing the LUR, prDNA-G and prDNA-inner were annotated and submitted to GenBank with respective accession numbers: JN133502, JN133503 and JN133504.

\section{Comparative genomics analysis of 66-p-347 and V.test}

The LUR and prDNA sequences of the 66-p-347 strain were joined into a complete genome (accession numbers 


\begin{tabular}{|c|c|c|}
\hline name & Sequence & Coordinates according to Genbank \\
\hline Bo1 Fwd & 5'- ATGGAGGGTGATGGATTCATG-3' & $460-440^{\mathrm{a}}$ \\
\hline Bo1 Rev & 5'- TTAAGGCCTCATTCCAGGAAG-3' & $272-292^{a}$ \\
\hline Bo5 Fwd & 5'- GCTACAGAAAATGGCCAGTAAAG-3' & $20366-20342^{a}$ \\
\hline Bo5 Rev & 5'- TCATGTCCTGAGTGGGTCTATG-3' & $19170-19191^{\mathrm{a}}$ \\
\hline Bo6 Fwd & 5'- ATGGTCATCCTAAATGCTCAAG -3' & $20297-20318^{a}$ \\
\hline Bo6 Rev & 5'- TCACCTAGTGTTGCAACCCC -3' & $20497-20478^{a}$ \\
\hline Bo7 Fwd & 5'- ATGGAGACAATTTCCATAAACTG -3' & $20994-20972^{a}$ \\
\hline Bo7 Rev & 5'- CTAGCTGGGGTAGAGTGATC - -3' & $20671-20690^{\mathrm{a}}$ \\
\hline ORF67.5 Fwd & 5'- ATGGCTGATGGTGATGTITAAG -3' & $93144-93123^{\mathrm{a}}$ \\
\hline ORF67.5 Rev & 5'- TCAATGTTTGTCCAGAGCACT -3' & $92881-92901^{a}$ \\
\hline Bo12 Fwd & 5'- ATGGGGGCGCTATTTGGGC -3' & $97442-97460^{\mathrm{a}}$ \\
\hline Bo12 Rev & 5'- TCAACTGATGAAACCCACCC - $3^{\prime}$ & $97525-97506^{\mathrm{a}}$ \\
\hline Bo13 Fwd & 5'- ATGCGTCTCGATGGCAAGC -3' & $98838-98856^{a}$ \\
\hline Bo13 Rev & 5'- CTATGGTTGTIIIITAAAGAAAATC -3' & $98981-98957^{a}$ \\
\hline ORF75 Fwd & 5'- ATGTATCCCAGATACAGTAACA -3' & $103606-103585^{a}$ \\
\hline ORF75 Rev & 5'- TTACATTTTATTTTTCAGACACCA -3' & $100274-100297^{a}$ \\
\hline prDNA Fwd 1 & 5'- GGAGCCCAAAACCAAAAGAG -3' & $870-889^{b}$ \\
\hline prDNA Rev 1 & 5'- CTCTTTTGGTTTTGGGCTCC -3' & $889-870^{b}$ \\
\hline prDNA Fwd 2 & 5'- CGTAGGCCTCACATTCAGC -3' & $908-926^{b}$ \\
\hline prDNA Rev 2 & 5'- GCTGAATGTGAGGCCTACG -3' & $926-908^{b}$ \\
\hline prDNA Fwd 3 & 5'- CGAGAGATGGTTCTTGCACA -3' & $940-959^{b}$ \\
\hline prDNA Rev 3 & 5'- TGTGCAAGAACCATCTCTCG -3' & $959-940^{b}$ \\
\hline BAC Rev & $5^{\prime}-$ TTGCCAATCCCAAAAAGAAG -3' & $9859-9878^{c}$ \\
\hline
\end{tabular}

a according to Genbank JN133502 sequence (BoHV-4 V.test strain long unique region)

${ }^{b}$ according to Genbank JN133504 sequence (BoHV-4 V.test strain prDNA inner region)

c according to Genbank AY665170.1 sequence (pBeloBAC modified)

NC_002665 and AF092919) and aligned against the joined LUR and prDNA-inner V.test sequences with ClustalW 2.0.10 [26]. Percent divergence, percent insertions and deletions, and percent $\mathrm{G}+\mathrm{C}$ content were computed (i) along the alignment on a 100 bp sliding window of step 3 bp and (ii) on all individually aligned proteins. Analyses and figures were conducted using $\mathrm{R}$ [27] and the seqinr [28] package in combination with ad hoc programs written in Python and using the Biopython libraries [29,30].

\section{RT-PCR analysis}

These experiments were performed as described elsewhere [31]. Briefly, subconfluent monolayers of MDBK cells were infected with BoHV4 V.test strain at a m.o.i. of $1 \mathrm{PFU} /$ cell. 18 hours after infection, cytoplasmic RNA was extracted, purified and treated for RT-PCR. The cDNA products were amplified by PCR using specific primers listed in Table 1.

\section{Results and discussion}

\section{BAC sequencing and genome assembly}

Pyrosequencing of herpesviral genomes is often limited by the high concentration of contaminating cellular DNA [32]. We therefore prepared the BoHV-4 V.test strain DNA from BAC maintained genomes and sequenced it using a high-throughput pyrosequencing approach [16]. This yielded 48,967 reads among which 47,800 were BoHV-4 specific (> 97\% of the reads). After assembly, the mean genome coverage was of the order of $96 x$. In comparison to the whole genome sequencing of another herpesvirus based on DNA isolated from virus particles, which exhibited a $13 \times$ average base pair coverage [32], our strategy showed a more than 7 -fold increase. This is probably mainly due to the high proportion of viral to cellular reads present in our dataset. Indeed, only 1,167 Escherichia coli contaminant reads had to be discarded from the data, indicating less than $2.38 \%$ of contaminated reads, compared to the previously reported $62.72 \%$ contaminating cellular reads in [32]. Our sequencing strategy based on a BAC cloning approach, thus revealed itself very powerful in terms of contamination and subsequent coverage.

\section{V.test genome analysis and comparison to other BoHV-4 strains}

The BoHV-4 genome has a B-type structure consisting of a long unique region (LUR) flanked by several polyrepetitive DNA units (prDNA). We assembled the 
complete LUR of the V.test strain BoHV-4 genome into a 108,241 bp sequence. The average $\mathrm{G}+\mathrm{C}$ content is of $41.21 \%$. This value as well as the $\mathrm{G}+\mathrm{C} \%$ variation observed on Figure 1 is in agreement with previously reported results on the 66-p-347 strain, namely on the high $\mathrm{G}+\mathrm{C}$ content of $\mathrm{R} 2 \mathrm{a}$ region [11]. The observed-toexpected CpG ratio is of 0.225 on the LUR and is compatible with the value measured on Bos taurus (0.234) [33] suggesting (i) a high degree of methylation of $\mathrm{CpG}$ nucleotides and (ii) similar methylation mechanisms acting on the viral and cellular genome.

As expected, the nucleotide identity between our assembled genome and previously published V.test strain sequence data was of $99.55 \%$ in average, falling into the ranges of comparison between 454 and Sanger sequencing [34].
Compared to the 66-p-347 strain, the V.test strain had previously shown divergence up to $12 \%$ on the region surrounding BORFB2 (ORF 16, v-Bcl-2) [11]. However, the lack of a complete genomic sequence for the V.test strain prevented from drawing a general conclusion concerning this divergence level. Compared to 66-p-347 strain, the overall V.test nucleotide identity is high (99.1\%), but shows a large variability at the genome level (Figure 1). As expected, the repetitive regions contained in the LUR (R1, R2a and R2b) exhibit a high nucleotide divergence, up to more than $40 \%$, as well as large gaps (Figure 1). This indicates that the very high divergence levels seem confined to specific repetitive genomic regions. However, some rather high divergence levels were also identified in other regions (Figure 1) and namely in ORF-containing regions such as ORF 10, Bo5, ORF 57, and ORF 68 region. We also note a

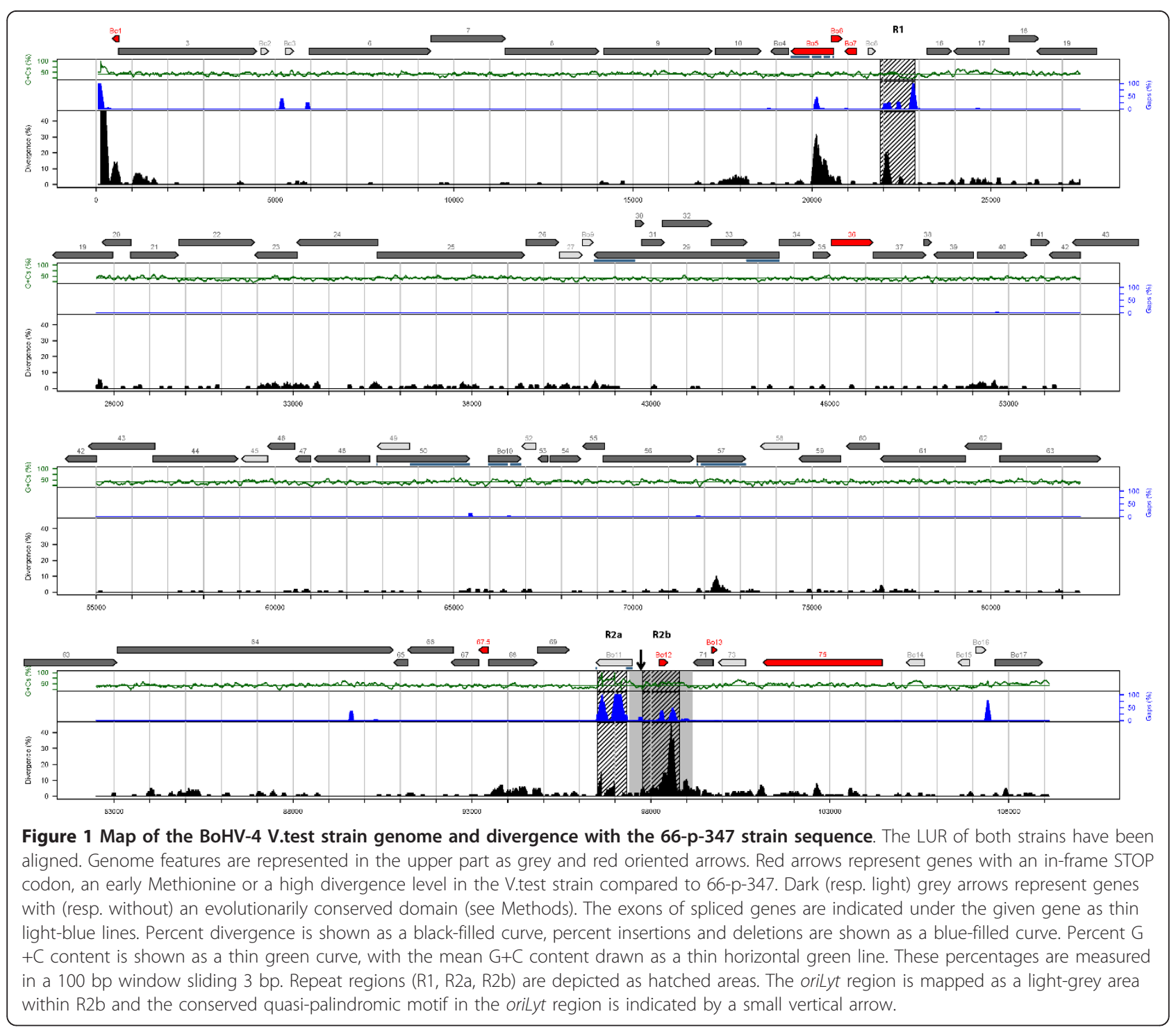


Table 2 Potential BoHV-4 V.test ORFs presenting conserved functional domains

\begin{tabular}{|c|c|c|c|}
\hline $\begin{array}{l}\text { BoHV-4 } \\
\text { ORF }\end{array}$ & Domain accession number & Functional annotation & Species distribution $^{a}$ \\
\hline ORF 3 & $\begin{array}{l}\text { COG0046, TIGR01735, TIGR01736, TIGR01739, } \\
\text { PF02769 }\end{array}$ & $\begin{array}{l}\text { Phosphoribosylformylglycinamidine (FGAM) synthase; } \\
\text { AIR synthase related protein }\end{array}$ & $\begin{array}{l}\text { Eukaryota; Bacteria; } \\
\text { Archaea; Viruses }\end{array}$ \\
\hline ORF 6 & PF00747 & ssDNA binding protein & Herpesviridae \\
\hline ORF 7 & PF01366 & Protein transporter activity & Herpesviridae \\
\hline ORF 8 & PF00606 & Surface glycoprotein & Herpesviridae \\
\hline ORF 9 & COG0417, TIGR00592, PF00136, PF03104, SM00486 & DNA polymerase type-B family & $\begin{array}{l}\text { Eukaryota; Bacteria; } \\
\text { Archaea; Viruses }\end{array}$ \\
\hline ORF 10 & PF04797 & dUTPase & Herpesviridae \\
\hline Bo4 & COG5183, SM00744 & $\begin{array}{l}\text { Protein involved in mRNA turnover and stability; zinc- } \\
\text { finger RING-variant domain }\end{array}$ & Eukaryota; Bacteria \\
\hline ORF 16 & SM00337 & $\mathrm{BCL}$ (B-Cell lymphoma); contains $\mathrm{BH} 1, \mathrm{BH} 2$ regions & Eukaryota; Bacteria; Viruses \\
\hline ORF 17 & PF00716 & Serine-type endopeptidase activity & Herpesviridae \\
\hline ORF 18 & PF03049 & UL79 family & Herpesviridae \\
\hline ORF 19 & PF01499 & Virus penetration and capsid assembly & Herpesviridae \\
\hline ORF 20 & PF01646 & UL24 family & Herpesviridae \\
\hline ORF 21 & PF00693, PF01712, PF08465 & $\begin{array}{l}\text { ATP binding; thymidine kinase activity; } \\
\text { phosphotransferase activity }\end{array}$ & Eukaryota; Bacteria; Viruses \\
\hline ORF 22 & PF02489 & Virion associated envelope glycoprotein & Herpesviridae \\
\hline ORF 23 & PF04682 & BTRF1 protein conserved region & Herpesviridae \\
\hline ORF 24 & PF03043 & UL87 family & Herpesviridae \\
\hline ORF 25 & PF03122 & Structural molecule activity & Herpesvirales \\
\hline ORF 26 & PF01802 & Structural molecule activity & Herpesvirales \\
\hline ORF 29 & PF02499, PF02500 & Probable role in DNA packaging & Herpesvirales \\
\hline ORF 30 & PF05338 & Unknown function (DUF717) & Gammaherpesvirinae \\
\hline ORF 31 & TIGR01234, PF03048 & UL92 family; L-ribulokinase & $\begin{array}{l}\text { Herpesvirales; } \\
\text { Embryophyta }\end{array}$ \\
\hline ORF 32 & PF04559 & DNA cleavage and packaging & Herpesviridae \\
\hline ORF 33 & PF03044 & Possible role in capsid maturation & Herpesviridae \\
\hline ORF 34 & PF03038 & UL95 family & Herpesviridae \\
\hline ORF 35 & PF05852 & Unknown function (DUF848) & Gammaherpesvirinae \\
\hline ORF 36 & COG0515, PF00069, SM00220 & $\begin{array}{l}\text { ATP binding; protein kinase activity; Serine/ } \\
\text { threonine protein kinase }\end{array}$ & $\begin{array}{l}\text { Eukaryota; Bacteria; } \\
\text { Archaea }\end{array}$ \\
\hline ORF 37 & PF01771, PF09588 & Exonuclease activity; DNA binding & $\begin{array}{l}\text { Eukaryota; Bacteria; } \\
\text { Viruses }\end{array}$ \\
\hline ORF 38 & PF10813 & Unknown function (DUF2733) & Herpesviridae \\
\hline ORF 39 & PF01528 & Integral membrane protein & Herpesviridae \\
\hline ORF 40 & PF03324 & Helicase-primase complex associated protein & Herpesviridae \\
\hline ORF 41 & PF05774 & Helicase-primase complex components & Gammaherpesvirinae \\
\hline ORF 42 & PF01677 & UL7-like protein & Herpesviridae \\
\hline ORF 43 & PF01763 & Possible role in cleavage and packaging & Herpesviridae \\
\hline ORF 44 & COG0507, PF02689 & $\begin{array}{l}\text { Helicase; ATP-dependent exoDNAse (exonuclease } \\
\text { V) }\end{array}$ & $\begin{array}{l}\text { Eukaryota; Bacteria; } \\
\text { Viruses }\end{array}$ \\
\hline ORF 46 & COG0692, TIGR00628, TIGR03443, PF03167 & Uracil DNA glycosylase & $\begin{array}{l}\text { Eukaryota; Bacteria; } \\
\text { Archaea; Viruses }\end{array}$ \\
\hline ORF 47 & PF11108 & Glycoprotein L & Herpesviridae \\
\hline ORF 48 & PF05734 & Unknown function (DUF832) & Herpesviridae \\
\hline ORF 50 & PF03326, PF04793 & Early-intermediate transcription factors & Gammaherpesvirinae \\
\hline Bo10 & PF05459, PF05812 & Transcriptional regulator proteins & Herpesviridae \\
\hline ORF 53 & PF03554 & Highly polymorphic glycoprotein & Herpesviridae \\
\hline ORF 54 & COG0756, TIGR00576, PF00692 & dUTPase & $\begin{array}{l}\text { Eukaryota; Bacteria; } \\
\text { Archaea; Viruses }\end{array}$ \\
\hline ORF 55 & PF04533 & U44 protein & Herpesviridae \\
\hline
\end{tabular}


Table 2 Potential BoHV-4 V.test ORFs presenting conserved functional domains (Continued)

\begin{tabular}{|c|c|c|c|}
\hline ORF 56 & PF03121 & UL52/UL70 DNA primase & $\begin{array}{l}\text { Eukaryota; dsDNA } \\
\text { Viruses }\end{array}$ \\
\hline ORF 57 & PF04633 & BMRF2 protein & Gammaherpesvirinae \\
\hline ORF 59 & PF04929 & DNA replication accessory factor & Gammaherpesvirinae \\
\hline ORF 60 & COG0208, PF00268 & Ribonucleotide reductase & $\begin{array}{l}\text { Eukaryota; Bacteria; } \\
\text { Archaea; Viruses }\end{array}$ \\
\hline ORF 61 & $\begin{array}{l}\text { COG0209, TIGR02504, TIGR02506, TIGR02510, } \\
\text { PF00317, PF02867 }\end{array}$ & Ribonucleotide reductase & $\begin{array}{l}\text { Eukaryota; Bacteria; } \\
\text { Archaea; Viruses }\end{array}$ \\
\hline ORF 62 & PF03327 & Capsid shell protein VP19C & Herpesviridae \\
\hline ORF 63 & PF04523 & Tegument protein U30 & Herpesviridae \\
\hline ORF 64 & PF04843 & Tegument protein, $\mathrm{N}$-terminal conserved region & Herpesviridae \\
\hline ORF 65 & PF06112 & Capsid protein & Gammaherpesvirinae \\
\hline ORF 66 & PF03117 & UL49 family & Herpesviridae \\
\hline ORF 67 & PF04541 & Virion protein U34 & Herpesviridae \\
\hline ORF 67.5 & PF03581 & UL33-like protein & Herpesviridae \\
\hline ORF 68 & PF01673 & Putative major envelope glycoprotein & Herpesviridae \\
\hline ORF 69 & PF02718 & UL31-like protein & Herpesviridae \\
\hline ORF 71 & PF01335, SM00031 & Death effector domain & Eukaryota; Viruses \\
\hline ORF 75 & $\begin{array}{l}\text { COG0046, COG0047, TIGR01735, TIGR01736, } \\
\text { TIGR01739, TIGR01857, PF02769 }\end{array}$ & $\begin{array}{l}\text { Phosphoribosylformylglycinamidine (FGAM) synthase; } \\
\text { AIR synthase related protein }\end{array}$ & $\begin{array}{l}\text { Eukaryota; Bacteria; } \\
\text { Archaea; Viruses }\end{array}$ \\
\hline Bo17 & PF02485 & Core-2/I-Branching enzyme & Eukaryota; Bacteria; Viruses \\
\hline
\end{tabular}

Conserved functional domains were determined for each BoHV-4 V.test ORF using METHOD and the domains accession numbers, functional annotation and the species distribution were listed. When several domains were conserved, the annotations were either merged when possible or juxtaposed. Domains present in herpesviridae conserved gene families are highlighted in bold (from Fu, 2008). (PFxxx: Pfam Accession Number; SMxxx: SMART Accession Number; COGxxx: COG Accession Number; TIGRxxx: TIGRFam Accession Number).

a Major taxonomic groups.

large deletion and a high divergence at the beginning of the LUR compared to the 66-p-347 strain. Overall, these differences in protein-coding region as well as in repetitive regions that bear predicted microRNA coding sequences [35] will require specific experiments to identify possible links with observed phenotypic differences between strains.

\section{Conserved protein-coding genes}

In order to develop an ab initio approach of gene annotation, we extracted all possible ORFs in all 6 frames from the complete genomic sequence of the BoHV-4 V. test strain. On each of these ORFs, we ran a Reverse PSI-BLAST [25] against all protein domains from the Conserved Domain Database [24]. ORFs containing an evolutionarily conserved domain were defined as the smallest ORF containing the longest CDD match (see Methods). This approach revealed 59 ORFs containing a conserved CDD domain (Table 2). All 59 detected ORFs corresponded to ORFs previously annotated in the 66-p347 strain (on a total of 79 ORFs listed in Table 3), indicating that $75 \%$ of BoHV-4 ORFs contain conserved domains. Most of these ORFs (37/59) contain domains that are either conserved at different levels in the Herpesvirales (either gammaherpesvirinae, herpesviridae or herpesvirales), or at a much larger scale that include Eukaryota, Bacteria and Archaea (22/59) (Table 2). This second set of genes might bear good candidates for genes having been the stage of lateral gene transfer events as observed for several herpesvirus genes [36] such as the BoHV-4 Bo17 gene that encodes a homologue of the cellular core 2 beta $-1,6-\mathrm{N}$-acetylglucosaminyl-transferase $M$ [37]. These results will deserve further studies to identify the evolutionary history responsible for these observations.

\section{Non-conserved protein-coding genes}

The remaining 20 annotated ORFs were determined by similarity to the 66-p-347 strain, and correspond for most of them to ORFs unique to BoHV-4 as described previously (Table 3) [11]. Some of these ORFs, however, contain odd characteristics that needed to be investigated (Figure 2, Additional file 1 Figures S1-9). Indeed Bo1, Bo6, Bo7, Bo12 and Bo13 genes of the BoHV-4 V.test strain present inframe STOP codons. Bo5 presents rather high divergency levels and large insertions/deletions (> 5\% of its coding sequence as shown in Figure 2) compared to the genomic sequence of the 66-p-347 strain. Moreover, ORFs 36, 67.5 and 75 , which bear an evolutionary conserved domain, present late methionines compared to the 66-p-347 annotation. Indeed, in ORF 36 (see Additional file 1 Figures S5), the smallest ORF containing an evolutionary conserved domain is slightly shorter than the one annotated in 66-p347 and there is no evidence that the previously annotated 
Table 3 Potential BoHV-4 V.test ORFs and homologues to HHV-8 and HHV-1

\begin{tabular}{|c|c|c|c|c|c|c|}
\hline $\begin{array}{l}\text { BoHV-4 } \\
\text { ORF }\end{array}$ & Strand & Start $^{\mathrm{a}}$ & Stop $^{a}$ & $\begin{array}{c}\text { HHV-8 } \\
\text { homologue }^{b}\end{array}$ & $\begin{array}{c}\text { HHV-1 } \\
\text { homologue }^{c}\end{array}$ & Annotation and comments \\
\hline$\overline{B 01}$ & - & 272 & 460 & - & - & Early in-frame STOP codon \\
\hline ORF 3 & + & 441 & 4307 & - & - & BORFA1; v-FGAM-synthase \\
\hline $\mathrm{BO} 2$ & + & 4435 & 4638 & - & - & \\
\hline Bo3 & + & 5072 & 5299 & - & - & \\
\hline ORF 6 & + & 5703 & 9107 & ORF 6 & UL 29 & single-stranded DNA-binding protein MDBP \\
\hline ORF 7 & + & 9112 & 11190 & ORF 7 & UL 28 & transport protein \\
\hline ORF 8 & + & 11180 & 13804 & ORF 8 & UL 27 & glycoprotein B \\
\hline ORF 9 & + & 13944 & 16961 & ORF 9 & UL 30 & DNA polymerase \\
\hline ORF 10 & + & 17057 & 18337 & ORF 10 & - & BORFB1 \\
\hline Bo4 & - & 18604 & 19101 & - & - & short ORF of immediate early transcript 1 \\
\hline Bo5 & - & 19170 & 20355 & K5 & - & long ORF of immediate early transcript 1 \\
\hline Bo6 & + & 20297 & 20590 & - & - & Early in-frame STOP codon \\
\hline Bo7 & - & 20670 & 20994 & - & - & Disrupted frame \\
\hline Bo8 & + & 21318 & 21521 & - & - & overlapping with late $1.7 \mathrm{~kb}$ RNA \\
\hline ORF 16 & + & 22967 & 23647 & ORF 16 & - & BORFB2; v-BCl-2 protein \\
\hline ORF 17 & - & 23710 & 25260 & ORF 17 & UL 26 & capsid protein \\
\hline ORF 18 & + & 25259 & 26077 & ORF 18 & - & \\
\hline ORF 19 & - & 26029 & 27705 & ORF 19 & UL 25 & tegument protein \\
\hline ORF 20 & - & 27407 & 28219 & ORF 20 & UL 24 & \\
\hline ORF 21 & + & 28203 & 29540 & ORF 21 & UL 23 & thymidine kinase \\
\hline ORF 22 & + & 29551 & 31674 & ORF 22 & UL 22 & glycoprotein H \\
\hline ORF 23 & - & 31671 & 32873 & ORF 23 & - & \\
\hline ORF 24 & - & 32851 & 35109 & ORF 24 & - & \\
\hline ORF 25 & + & 35099 & 39220 & ORF 25 & UL 19 & major capsid protein \\
\hline ORF 26 & + & 39256 & 40170 & ORF 26 & UL 18 & capsid protein \\
\hline ORF 27 & + & 40184 & 40829 & ORF 27 & - & \\
\hline Bo9 & + & 40831 & 41130 & - & - & \\
\hline ORF 29 & - & 41154 & 46328 & ORF 29 & UL 15 & cleavage/packaging protein \\
\hline ORF 30 & + & 42306 & 42548 & ORF 30 & - & \\
\hline ORF 31 & + & 42482 & 43123 & ORF 31 & - & \\
\hline ORF 32 & + & 43069 & 44439 & ORF 32 & UL 17 & viral DNA cleavage/packaging protein \\
\hline ORF 33 & + & 44432 & 45430 & ORF 33 & UL 16 & \\
\hline ORF 34 & + & 46327 & 47313 & ORF 34 & - & \\
\hline ORF 35 & + & 47285 & 47758 & ORF 35 & - & \\
\hline ORF 36 & + & 47787 & 48950 & ORF 36 & UL 13 & kinase \\
\hline ORF 37 & + & 48958 & 50427 & ORF 37 & UL 12 & alkaline exonuclease \\
\hline ORF 38 & + & 50379 & 50585 & ORF 38 & - & \\
\hline ORF 39 & - & 50652 & 51761 & ORF 39 & UL 10 & glycoprotein M \\
\hline ORF 40 & + & 51877 & 53247 & ORF 40 & UL 8 & helicase-primase complex component \\
\hline ORF 41 & + & 53360 & 53881 & ORF 41 & - & helicase-primase complex component \\
\hline ORF 42 & - & 53873 & 54748 & ORF 42 & UL 7 & \\
\hline ORF 43 & - & 54525 & 56375 & ORF 43 & UL 6 & capsid protein \\
\hline ORF 44 & + & 56323 & 58701 & ORF 44 & UL 5 & helicase \\
\hline ORF 45 & - & 58805 & 59530 & ORF 45 & - & \\
\hline ORF 46 & - & 59530 & 60291 & ORF 46 & UL 2 & uracil-DNA-glycosidase \\
\hline ORF 47 & - & 60309 & 60731 & ORF 47 & - & glycoprotein $L$ \\
\hline ORF 48 & - & 60838 & 62382 & ORF 48 & - & \\
\hline ORF 50 & + & 62586 & 65179 & ORF 50 & - & immediate early transcript $2 ; R$ transactivator protein \\
\hline ORF 49 & - & 62600 & 63499 & ORF 49 & - & \\
\hline Bo10 & + & 65696 & 66595 & - & UL 54 & glycoprotein gp80 \\
\hline ORF 52 & - & 66621 & 67007 & ORF 52 & - & \\
\hline
\end{tabular}


Table 3 Potential BoHV-4 V.test ORFs and homologues to HHV-8 and HHV-1 (Continued)

\begin{tabular}{|c|c|c|c|c|c|c|}
\hline ORF 53 & - & 67073 & 67345 & ORF 53 & - & \\
\hline ORF 54 & + & 67414 & 68262 & ORF 54 & UL 50 & dUTPase \\
\hline ORF 55 & - & 68321 & 68923 & ORF 55 & - & \\
\hline ORF 56 & + & 68887 & 71418 & ORF 56 & UL 52 & DNA replication protein \\
\hline ORF 57 & + & 71512 & 72870 & ORF 57 & - & possible post-transcriptional transactivator \\
\hline ORF 58 & - & 73294 & 74346 & ORF 58 & - & \\
\hline ORF 59 & - & 74360 & 75535 & ORF 59 & - & DNA replication protein \\
\hline ORF 60 & - & 75688 & 76605 & ORF 60 & UL 40 & ribonucleotide reductase small subunit \\
\hline ORF 61 & - & 76639 & 79020 & ORF 61 & UL 39 & ribonucleotide reductase large subunit \\
\hline ORF 62 & - & 79002 & 80021 & ORF 62 & UL 38 & assembly/DNA maturation protein \\
\hline ORF 63 & + & 79978 & 82797 & ORF 63 & - & tegument protein \\
\hline ORF 64 & + & 82812 & 90488 & ORF 64 & UL 36 & tegument protein \\
\hline ORF 65 & - & 90504 & 90896 & ORF 65 & - & capsid protein \\
\hline ORF 66 & - & 90893 & 92167 & ORF 66 & - & \\
\hline ORF 67 & - & 92107 & 92877 & ORF 67 & UL 34 & tegument protein \\
\hline ORF 67.5 & - & 92881 & 93144 & ORF 67.5 & UL 33 & Disrupted (late) methionine \\
\hline ORF 68 & + & 93155 & 94504 & ORF 68 & UL 32 & probable glycoprotein \\
\hline ORF 69 & + & 94512 & 95405 & ORF 69 & UL 31 & \\
\hline Bo11 & - & 96158 & 96703 & - & - & \\
\hline Bo12 & + & 97442 & 97684 & - & - & Early in-frame STOP codon \\
\hline ORF 71 & - & 98328 & 98876 & K13/ORF 71 & - & BORFE2; v-FLIP \\
\hline Bo13 & + & 98838 & 98983 & - & - & Disrupted frame \\
\hline ORF 73 & - & 99022 & 99783 & ORF 73 & - & BORFE3, LANA homologous \\
\hline ORF 75 & - & 100274 & 103606 & ORF 75 & - & $\begin{array}{l}\text { Disrupted (late) methionine; tegument protein/v-FGAM- } \\
\text { synthetase }\end{array}$ \\
\hline Bo14 & - & 104273 & 104785 & - & - & \\
\hline Bo15 & - & 105724 & 106038 & - & - & \\
\hline Bo16 & + & 106225 & 106494 & - & - & \\
\hline Bo17 & + & 106681 & 108003 & - & - & viral beta-1,6-N-acetylglucosaminyltransferase \\
\hline
\end{tabular}

${ }^{a}$ Positions of the respective ORFs of BoHV-4 on the LUR sequence. These are given from the first nucleotide of the start codon ATG to the last nucleotide of the stop codon.

${ }^{\mathrm{b}}$ Correspondance to HHV-8 genes is according to Zimmermann (2001).

c Correspondance to HHV-1 genes was based on the presence of conserved domain with a BoHV-4 gene. Genes containing evolutionary conserved domains are highlighted in bold italic. The genes conserved in Herpesviridae are highlighted in bold (from Fu, 2008).

methionine is the correct one. However, comparison with homologous genes in other rhadinoviruses suggests that the start codon proposed in the 66-p-347 annotated sequence is the most likely. In ORF 67.5 (see Additional file 1 Figures S6), there is a point substitution in the 66-p347 annotated ATG leading to the identification of a subsequent ATG as the V.test methionine. Finally, ORF 75 presents a small phase-disrupting indel in its 5' end (see Additional file 1 Figures S9), leading to the absence of the 66-p-347 annotated methionine in the V.test strain. All these annotated genes requested therefore an investigation of their transcription in mRNA products.

As these sequence properties could be specific to the BAC clone of the BoHV-4 V.test strain, we investigated the transcription of these genes on MDBK cells infected with the BoHV-4 V.test WT strain as described in the methods. The primers used are described in Table 1 and highlighted in Additional file 1. For all couple of primers, cDNA from BoHV-4-infected MDBK cells gave rise to the expected PCR products (Figure 3). The absence of contaminant viral DNA in the mRNA preparations was confirmed by a lack of PCR product without reverse transcriptase. The size of the Bo5 RT-PCR product was also consistent with its known mRNA splicing (868 bp rather than $1140 \mathrm{bp}$ ). Moreover, the sequences of these RT-PCR products were in agreement with the BoHV-4 V.test sequence derived from our BAC cloned genome (data not shown). Therefore, we can conclude that all these coding sequences are transcribed during BoHV-4 infection of MDBK cells. However, further investigation is needed to determine the presence of proteins and ensure their accurate annotation.

\section{BoHV-4 V.test replication origin}

A large region containing the potential lytic replication origin (oriLyt) of the BoHV-4 66-p-347 strain was 


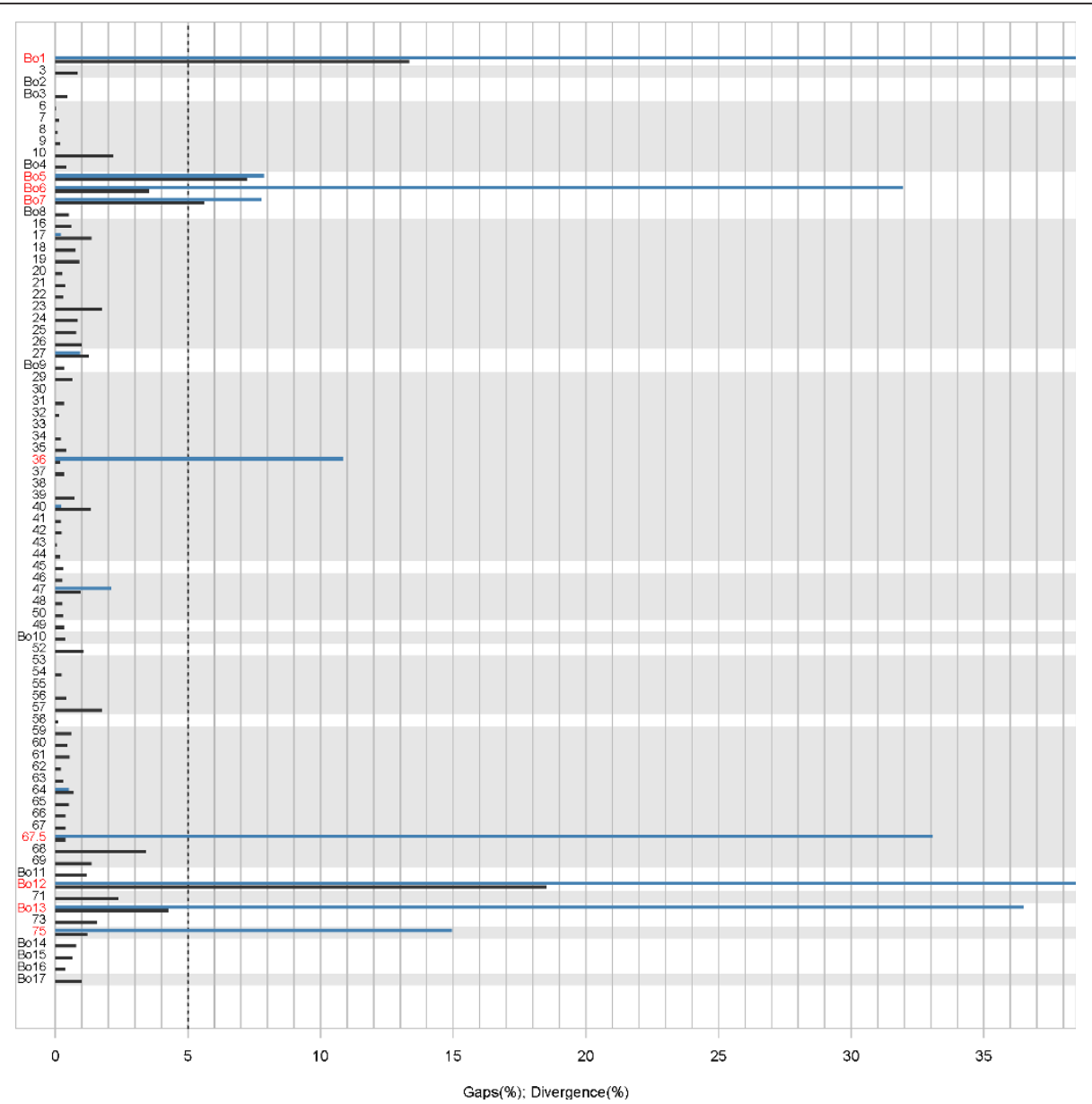

Figure 2 Proteins in V.test: divergence with the previously published 66-p-347 strain. Percentage divergence and percentages indels on the aligned amino-acid sequences are represented as, respectively, black and light-blue bars. The dotted black line represents a 5\% threshold. Genes containing an evolutionarily conserved domain (see Methods) are represented on a light-grey background. Previously annotated genes presenting in the V.test strain an in-frame stop codon, a late Methionine or large divergence levels compared to the 66-p-347 strain are indicated in red.

determined by Zimmermann et al [11]. Based on this information, we mapped this region on the V.test genome (Figure 1). This region contains Bo12, the R2b region and partially overlaps with Bo11. Compared to the 66-p-347 strain sequence, the corresponding region in the V.test genome is highly divergent (Figure 4). Although this region shows high divergence rates, we expected the replication origin to be conserved between the two BoHV-4 strains. Previous work on other herpesviruses has identified in oriLyt the presence of palindromic motifs essential for viral replication [38-40]. When we compared the potential region containing oriLyt in the two strains, a single conserved palindromic region was observed (AATCCAGGCCCCTGATTGGTAGATTGC TGAAAGCCAATCAGGGGCCTGGATT, Figure 4). Interestingly, this region forms a perfect hairpin structure (Figure 4B) that resembles DNA structures formed at other herpesvirus origins $[41,42]$ and may therefore represent a common secondary structure used by all herpesvirus family members during the initiation of DNA replication. In the future, this structure will be tested as a candidate for an essential oriLyt replication motif.

\section{BoHV-4 V.test polyrepetitive DNA}

In the BAC clone, previous restriction profiles had determined a hypermolar prDNA band indicating that the BAC contained several prDNA units [12]. Therefore, the major pitfall in the assembly of the BoHV-4 V.test strain was the determination of the prDNA sequence. Indeed, (i) the higher per base coverage on this region due to repetition of prDNA units, (ii) the high GC content, along with (iii) the presence of several long repeats within the prDNA and (iv) the variability observed between prDNA units [14] made it extremely difficult to resolve and assemble with 


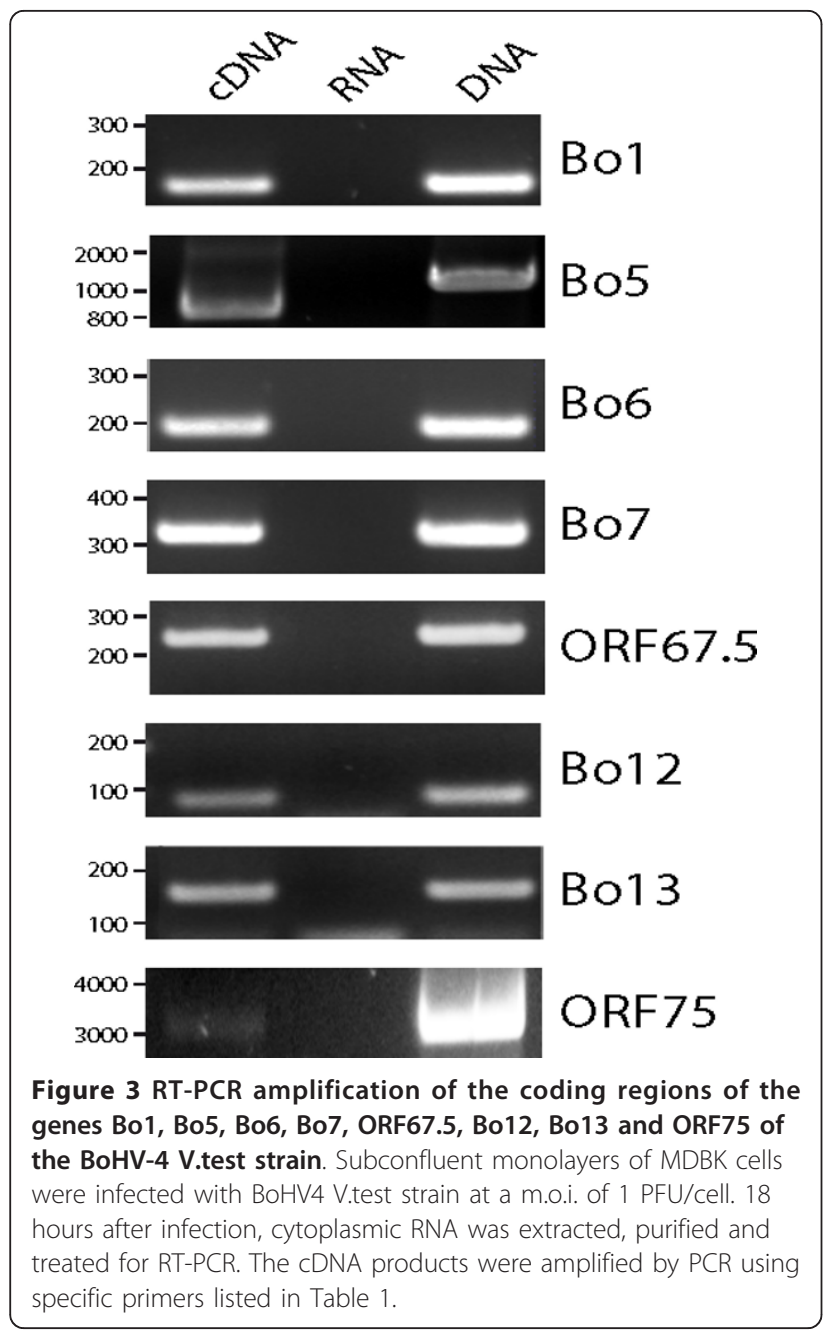

pyrosequencing data alone. Interestingly, it has been shown for several rhadinoviruses that the left junction between the prDNA and the LUR is the site of genome rearrangements and that sequences of the prDNA are found within the first base pairs of the LUR. These properties make this region very difficult to sequence [43-47].

Therefore, we adopted a hybrid strategy consisting in adding some ABI-Sanger reads (with the primers described in Table 1) to guide the 454 assembly on the prDNA region (see Methods).

Bublot, et al. [14] described the different prDNA unit variants present in BoHV-4 V.test, and namely the differences between prDNA units. Firstly, the prDNA units vary according to the number of repetitions of a $\sim 200$ bp Pst-I bordered fragment. Secondly, the last prDNA before the prDNA/LUR junction (prDNA-G) displays a different ending than the inner prDNA units [14]. Our method allowed us to disentangle the repeats and to assemble a contig containing a whole prDNA unit (2,440 bp) along with the left prDNA-LUR junction. This prDNA unit, corresponding to prDNA-G following Bublot et al. [14], was extracted from the contig and annotated. A second contig from this hybrid assembly yielded the prDNA/prDNA junction. The presence of the prDNA/prDNA junction in our assembly confirmed the presence of at least two prDNA units in our BAC clone and allowed us to build a complete prDNA-inner unit (see Methods). The assembled prDNA-G and inner prDNA units have sizes of 2,440 bp and 2,607 bp respectively. Both these units are in agreement with their previously published restriction maps [14].

Specifically, we showed that, comparatively to the 66p-347 strain, the V.test prDNA-inner unit presents several indels including two large indels in the repetitive PstI region (Figure 5). This PstI-rich repetitive region seems to be the one presenting the most variation as it also presents comparatively large differences between prDNA units within the same strain. Indeed, Bublot $e t$ al. [14] roughly determined the size of the V.test major prDNA-inner unit to be around 2,650 bp due to the presence of 4 repetitions of the two small PstI bordered fragments.
A

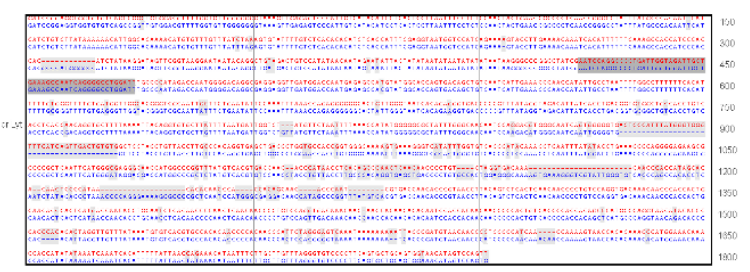

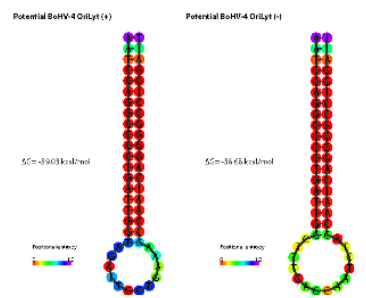

Figure 4 Prediction of BoHV-4 V.test OriLyt. A. Alignment of the V.test strain (above) and 66-p-347 strain (below) regions predicted to contain the Orilyt in the 66-p-347 strain. The differences observed in the alignment are highlighted in light grey. The predicted potential OriLyt is highlighted in dark grey. B. The predicted secondary structures of the top (+) and bottom (-) strands of the predicted BoHV-4 Orilyt sequence were analyzed using the Vienna RNA website program RNAfold with DNA parameters. The predicted free energy ( $\triangle \mathrm{G})$ of each structure is given, as well as the positional entropy of each nucleotide. 


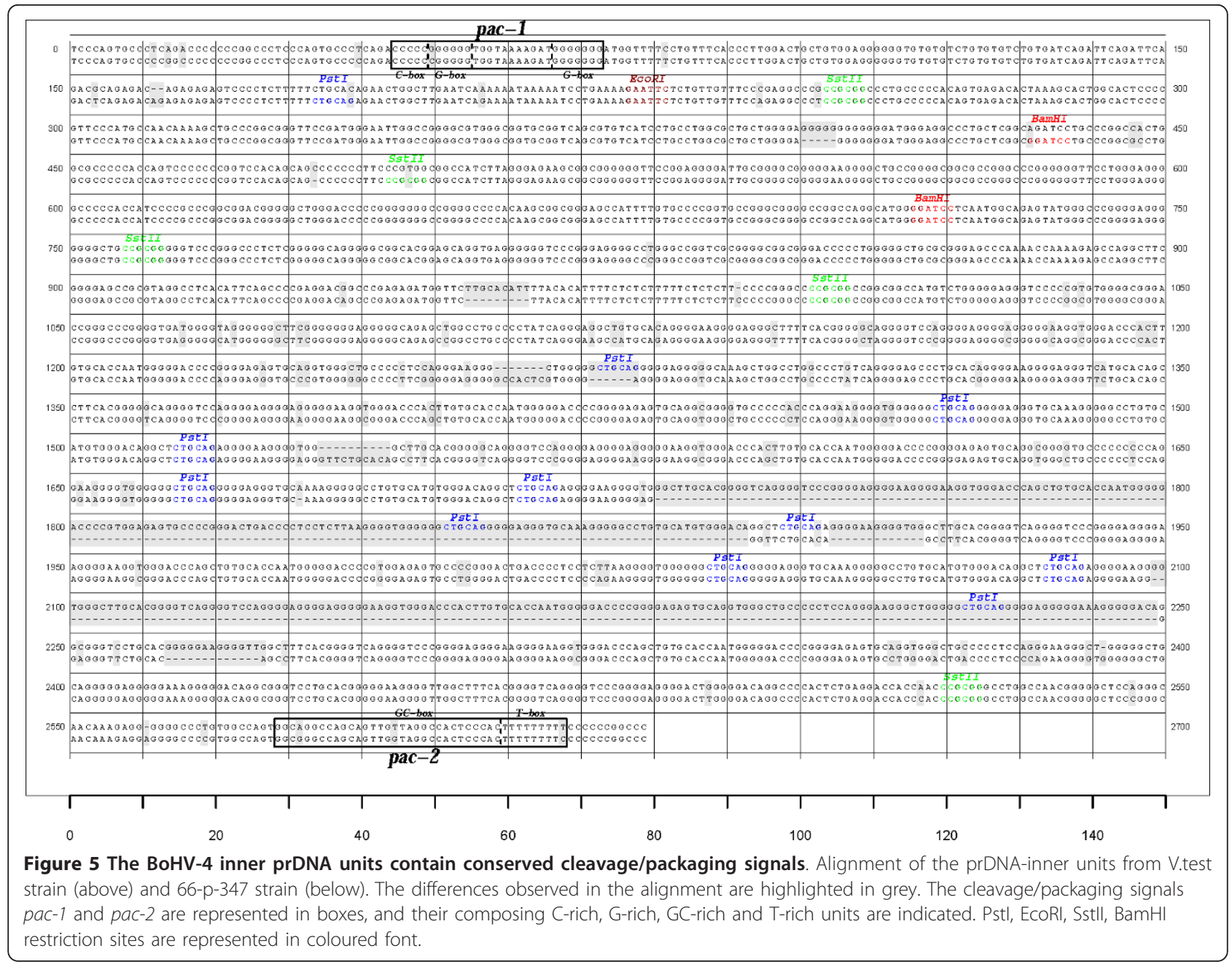

In the prDNA-G unit, we established that these two small PstI-bordered fragments make up a fragment of $186 \mathrm{bp}$ and that these are indeed repeated 4 times (Figure 6). In the prDNA-inner unit, we determined that the last PstI-bordered fragment is actually a variation of the $186 \mathrm{bp}$ fragment where the inner Pst-I site is slightly modified (Figure 6). Therefore, the rough 200 bp size discrepancy between the prDNA-G $(2,440$ $\mathrm{bp})$ and the prDNA-inner units $(2,607 \mathrm{bp})$ is due to the presence of a slightly modified repetition of the previous segment. These results are compatible with the restriction profiles presented in Bublot et al. [14] as detailed by the positions of several restriction sites on Figure 6.

In addition to the variations in the PstI-bordered repetitions, one of the major differences between the prDNA-inner units and the prDNA-G lies in their 5' end. Indeed, the prDNA-inner contains a conserved pac-2 cleavage/packaging signal in its right terminal region, which is not the case of prDNA-G (Figure 6).
Both units however, possess a conserved pac-1 cleavage/packaging signal in their left terminal region. Interestingly, the pac-1 and pac-2 cleavage and packaging signals show a good conservation between 66-p347 and V.test's inner units, despite the presence of these signals in a repeated region bearing high divergence levels. Broll et al. [15] have determined, by transient cleavage/packaging assay, that a single prDNA unit is sufficient for cleavage and packaging. However, from the absence of a conserved pac-2 motif in the prDNA-G, we suggest that, even if a single inner prDNA unit is indeed sufficient for cleavage and packaging, the prDNA-G alone would not suffice. This would therefore indicate that two prDNA units at least are necessary in the context of naturally occurring BoHV-4 genomes for correct cleavage and packaging. The packaging of herpesvirus genomes is still not fully understood, however, detailed studies in herpes simplex virus type 1 (HSV-1), human and murine cytomegaloviruses (HCMV and MCMV) have 


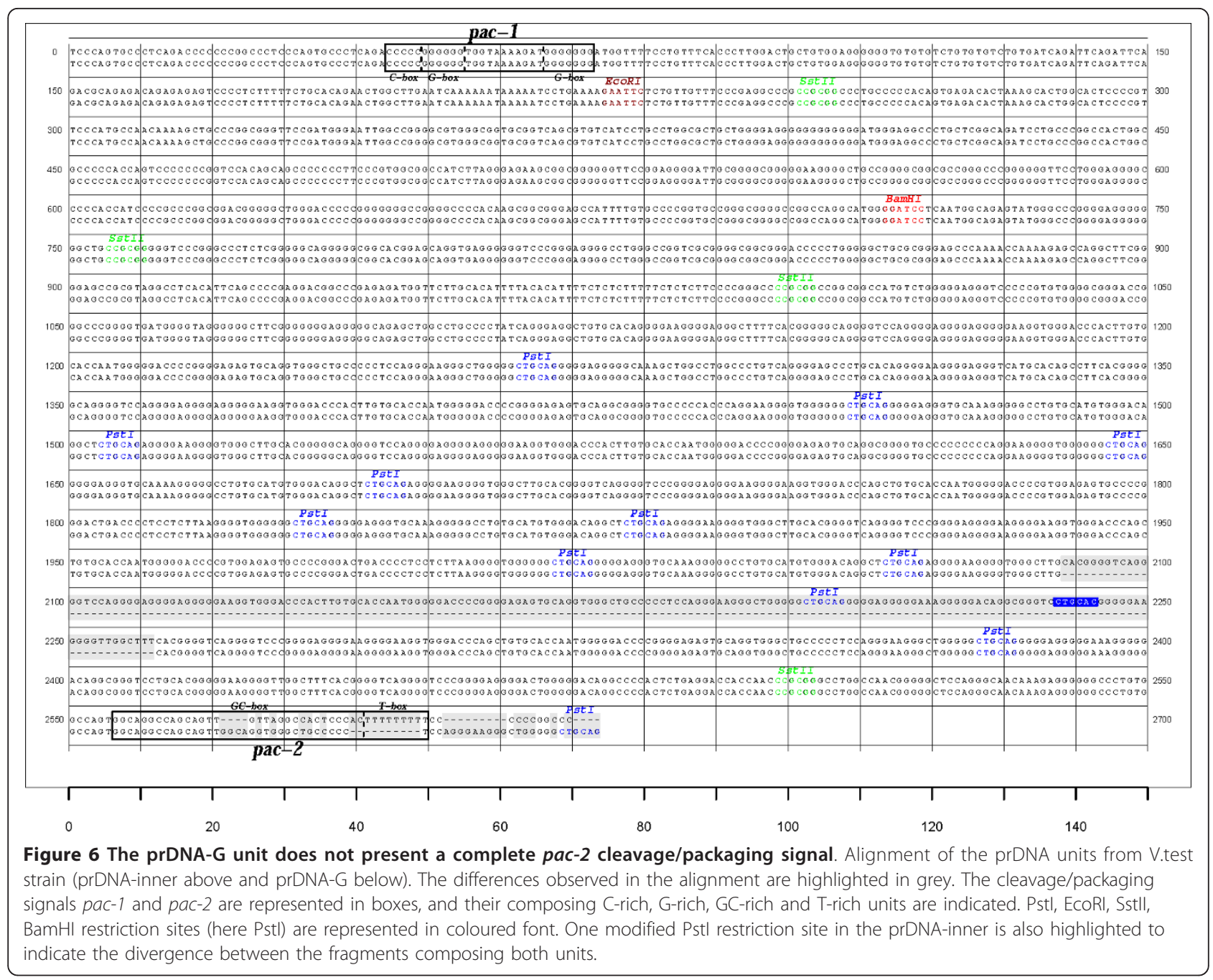

highlighted the roles of the major conserved motifs and suggested the following general mechanism by which concatemers are cleaved and packaged [48-50]. Firstly, the T-box of the pac-2 signal is essential for the cleavage that initiates DNA packaging. Cleavage occurs at a fixed distance from the pac-2 T-box, and the resulting end that contains the pac-2 GC-box and other cis acting elements is inserted into the procapsid. Packaging is therefore directional and proceeds from $p a c-2$ towards the $p a c-1$ terminus [48]. A second cleavage event, directed by pac-1, then terminates DNA packaging. If we apply this model to BoHV-4, the divergence of the pac-2 signal in prDNA-G, namely the absence of a T-box, indicates that it is not a functional pac-2 initiation signal. As the genome packaging is directional from pac-2 to pac-1 (therefore, from the right to the left end of the genome), the lack of a pac-2 initiation signal in prDNA-G ensures that no packaging would lead to a remaining concatemer lacking a left end prDNA. This would therefore guarantee that genomes bearing at least one left and one right end prDNA unit are encapsulated into virions. This model and its implications will require further investigations in the future.

\section{Conclusions}

BAC-cloning of the BoHV-4 V.test strain has greatly facilitated the use of this virus as a model for human pathogenic gammaherpesviruses. However, until now, the complete genome sequence of this strain was unavailable. In this study, we have determined the complete genome sequence of the BoHV-4 V.test strain. In comparison with the previously sequenced 66-p-347 strain, we identified important differences in 9 potential open reading frames. Moreover, sequence analyses allowed us to identify genome features that are potentially important for viral replication. All together, these results should have implications for the study of BoHV-4 and herpesviruses in general. 


\section{Additional material}

Additional file 1: Alignments of the nucleotide and predicted amino acid sequences of Bo1 (Figure S1), Bo5 (Figure S2), Bo6 (Figure S3), Bo7 (Figure S4), ORF36 (Figure S5), ORF67.5 (Figure S6), Bo12 (Figure S7), Bo13 (Figure S8) and ORF75 (Figure S9) of BoHV-4 V. test and 66-p-347 strains. Nucleotide sequences aligned at the aminoacid level are represented for BoHV-4 V.test (red) and 66-p-347 strains (blue). Mismatching residues are highlighted in a shaded grey box. The predicted amino-acid sequences are respectively drawn for V.test and for 66-p-347 above and below the nucleotide sequences. The STOP codons are highlighted by small colored boxes. The annotated Methionine are highlighted in bold font. In the Bo5 sequence, introns are represented by boxes. Positions of the specific primers used in Figure 3 are underlined.

\section{Acknowledgements}

LP is supported by a post-doctoral fellowship from the University of Liège. $B M, C L$ and $L G$ are Research Fellows and Research Associate of the "Fonds de la Recherche Scientifique - Fonds National Belge de la Recherche Scientifique" (F.R.S. - FNRS), respectively. This work was supported by the following grants: starting grant (D-09/11) and GLYVIR ARC of the University of Liège and scientific impulse grant of the F.R.S. - FNRS $n^{\circ} F .4510 .10$.

\section{Authors' contributions}

$L P$ analyzed the data in silico, participated in the RT-PCR assay and drafted the manuscript. BM prepared the viral DNA, participated in data analysis and performed the RT-PCR assay. AV and CL participated in data analysis. LG analyzed the data and drafted the manuscript. All authors read and approved the final manuscript.

\section{Competing interests}

The authors declare that they have no competing interests.

Received: 17 June 2011 Accepted: 16 August 2011

Published: 16 August 2011

\section{References}

1. Henle G, Henle W, Clifford P, Diehl V, Kafuko GW, Kirya BG, Klein G, Morrow RH, Munube GM, Pike P, et al: Antibodies to Epstein-Barr virus in Burkitt's lymphoma and control groups. J Natl Cancer Inst 1969, 43:1147-1157.

2. Verma SC, Robertson ES: Molecular biology and pathogenesis of Kaposi sarcoma-associated herpesvirus. FEMS Microbiol Lett 2003, 222:155-163.

3. Thorley-Lawson DA, Gross A: Persistence of the Epstein-Barr virus and the origins of associated lymphomas. N Engl J Med 2004, 350:1328-1337.

4. Davison AJ, Eberle R, Ehlers B, Hayward GS, McGeoch DJ, Minson AC, Pellett PE, Roizman B, Studdert MJ, Thiry E: The order Herpesvirales. Arch Virol 2009, 154:171-177.

5. Thiry E, Bublot M, Dubuisson J, Van Bressem MF, Lequarre AS, Lomonte P, Vanderplasschen A, Pastoret PP: Molecular biology of bovine herpesvirus type 4. Vet Microbiol 1992, 33:79-92

6. Bartha A, Juhasz $\mathrm{M}$, Liebermann $\mathrm{H}$ : Isolation of a bovine herpesvirus from calves with respiratory disease and keratoconjunctivitis. A preliminary report. Acta Vet Acad Sci Hung 1966, 16:357-358.

7. Mohanty SB, Hammond RC, Lillie MG: A new bovine herpesvirus and its effect on experimentally infected calves. Brief report. Arch Gesamte Virusforsch 1971, 33:394-395.

8. Rossiter PB, Gumm ID, Stagg DA, Conrad PA, Mukolwe S, Davies FG, White $\mathrm{H}$ : Isolation of bovine herpesvirus-3 from African buffaloes (Syncerus caffer). Res Vet Sci 1989, 46:337-343.

9. Dewals B, Thirion M, Markine-Goriaynoff N, Gillet L, de Fays K, Minner F, Daix V, Sharp PM, Vanderplasschen A: Evolution of Bovine herpesvirus 4: recombination and transmission between African buffalo and cattle. $J$ Gen Virol 2006, 87:1509-1519.

10. Dewals B, Gillet L, Gerdes T, Taracha EL, Thiry E, Vanderplasschen A: Antibodies against bovine herpesvirus 4 are highly prevalent in wild African buffaloes throughout eastern and southern Africa. Vet Microbiol 2005, 110:209-220
11. Zimmermann W, Broll H, Ehlers B, Buhk HJ, Rosenthal A, Goltz M: Genome sequence of bovine herpesvirus 4, a bovine Rhadinovirus, and identification of an origin of DNA replication. J Virol 2001, 75:1186-1194.

12. Gillet L, Daix V, Donofrio G, Wagner M, Koszinowski UH, China B, Ackermann M, Markine-Goriaynoff N, Vanderplasschen A: Development of bovine herpesvirus 4 as an expression vector using bacterial artificial chromosome cloning. J Gen Virol 2005, 86:907-917.

13. Thiry E, Pastoret PP, Dessy-Doizé C, Hanzen C, Calberg-Bacq CM: Herpesvirus in infertile bull's testicle. Vet rec 1981, 108:426.

14. Bublot M, Van Bressem MF, Thiry E, Dubuisson J, Pastoret PP: Bovine herpesvirus 4 genome: cloning, mapping and strain variation analysis. $J$ Gen Virol 1990, 71(Pt 1):133-142.

15. Broll H, Buhk HJ, Zimmermann W, Goltz M: Structure and function of the prDNA and the genomic termini of the gamma2-herpesvirus bovine herpesvirus type 4. J Gen Virol 1999, 80(Pt 4):979-986.

16. Margulies M, Egholm M, Altman WE, Attiya S, Bader JS, Bemben LA, Berka J, Braverman MS, Chen YJ, Chen Z, et al: Genome sequencing in microfabricated high-density picolitre reactors. Nature 2005, 437:376-380

17. Altschul SF, Gish W, Miller W, Myers EW, Lipman DJ: Basic local alignment search tool. J Mol Biol 1990, 215:403-410.

18. Lomonte P, Bublot M, van Santen V, Keil GM, Pastoret PP, Thiry E: Analysis of bovine herpesvirus 4 genomic regions located outside the conserved gammaherpesvirus gene blocks. J Gen Virol 1995, 76(Pt 7):1835-1841.

19. Chevreux B, Pfisterer T, Drescher B, Driesel AJ, Muller WE, Wetter T, Suhai S: Using the miraEST assembler for reliable and automated mRNA transcript assembly and SNP detection in sequenced ESTs. Genome Res 2004, 14:1147-1159.

20. Ewing B, Green P: Base-calling of automated sequencer traces using phred. II. Error probabilities. Genome Res 1998, 8:186-194.

21. Ewing B, Hillier L, Wendl MC, Green P: Base-calling of automated sequencer traces using phred. I. Accuracy assessment. Genome Res 1998, 8:175-185.

22. Chou HH, Holmes MH: DNA sequence quality trimming and vector removal. Bioinformatics 2001, 17:1093-1104.

23. Staden R, Beal KF, Bonfield JK: The Staden package, 1998. Methods Mol Biol 2000, 132:115-130

24. Marchler-Bauer A, Anderson JB, Chitsaz F, Derbyshire MK, DeWeese-Scott C, Fong JH, Geer LY, Geer RC, Gonzales NR, Gwadz M, et al: CDD: specific functional annotation with the Conserved Domain Database. Nucleic Acids Res 2009, 37:D205-210.

25. Schaffer AA, Wolf $\mathrm{YI}$, Ponting CP, Koonin EV, Aravind L, Altschul SF: IMPALA: matching a protein sequence against a collection of PSI-BLASTconstructed position-specific score matrices. Bioinformatics 1999, 15:1000-1011.

26. Larkin MA, Blackshields G, Brown NP, Chenna R, McGettigan PA, McWilliam H, Valentin F, Wallace IM, Wilm A, Lopez R, et al: Clustal W and Clustal $\times$ version 2.0. Bioinformatics 2007, 23:2947-2948.

27. Team RDC: R: A Language and Environment for Statistical Computing Vienna: R Foundation for Statistical Computing; 2010.

28. Charif D, Lobry J: SeginR 1.0-2: a contributed package to the $R$ project for statistical computing devoted to biological sequences retrieval and analysis New York: Springer Verlag; 2007.

29. Cock PJ, Antao T, Chang JT, Chapman BA, Cox CJ, Dalke A, Friedberg I, Hamelryck T, Kauff F, Wilczynski B, de Hoon MJ: Biopython: freely available Python tools for computational molecular biology and bioinformatics. Bioinformatics 2009, 25:1422-1423.

30. van Rossum G, Drake F Jr: The Python Language Reference Manual (version 2.5) Network Theory Ltd; 2006.

31. Machiels B, Lete C, de Fays K, Mast J, Dewals B, Stevenson PG, Vanderplasschen A, Gillet L: Bovine Herpesvirus-4 Bo10 gene encodes a non-essential viral envelope protein that regulates viral tropism through both positive and negative effects. J Virol 2010

32. Spatz SJ, Rue CA: Sequence determination of a mildly virulent strain (CU2) of Gallid herpesvirus type 2 using 454 pyrosequencing. Virus Genes 2008, 36:479-489.

33. Elsik CG, Tellam RL, Worley KC, Gibbs RA, Muzny DM, Weinstock GM, Adelson DL, Eichler EE, Elnitski L, Guigo R, et al: The genome sequence of taurine cattle: a window to ruminant biology and evolution. Science 2009, 324:522-528.

34. Wicker T, Schlagenhauf E, Graner A, Close TJ, Keller B, Stein N: 454 sequencing put to the test using the complex genome of barley. BMC Genomics 2006, 7:275. 
35. Walz N, Christalla T, Tessmer U, Grundhoff A: A global analysis of evolutionary conservation among known and predicted gammaherpesvirus microRNAs. J Virol 2010, 84:716-728.

36. Fu M, Deng R, Wang J, Wang X: Detection and analysis of horizontal gene transfer in herpesvirus. Virus Res 2008, 131:65-76.

37. Vanderplasschen A, Markine-Goriaynoff N, Lomonte P, Suzuki M, Hiraoka N, Yeh JC, Bureau F, Willems L, Thiry E, Fukuda M, Pastoret PP: A multipotential beta -1,6- $\mathrm{N}$-acetylglucosaminyl-transferase is encoded by bovine herpesvirus type 4. Proc Natl Acad Sci USA 2000, 97:5756-5761.

38. Portes-Sentis S, Sergeant A, Gruffat H: A particular DNA structure is required for the function of a cis-acting component of the Epstein-Barr virus OriLyt origin of replication. Nucleic Acids Res 1997, 25:1347-1354.

39. Zhu Y, Huang L, Anders DG: Human cytomegalovirus orilyt sequence requirements. J Virol 1998, 72:4989-4996.

40. AuCoin DP, Colletti KS, XU Y, Cei SA, Pari GS: Kaposi's sarcoma-associated herpesvirus (human herpesvirus 8 ) contains two functional lytic origins of DNA replication. J Virol 2002, 76:7890-7896.

41. Rennekamp AJ, Wang P, Lieberman PM: Evidence for DNA hairpin recognition by Zta at the Epstein-Barr virus origin of lytic replication. $J$ Virol 2010, 84:7073-7082.

42. Aslani A, Macao B, Simonsson S, Elias P: Complementary intrastrand base pairing during initiation of Herpes simplex virus type 1 DNA replication. Proc Natl Acad Sci USA 2001, 98:7194-7199.

43. Russo JJ, Bohenzky RA, Chien MC, Chen J, Yan M, Maddalena D, Parry JP, Peruzzi D, Edelman IS, Chang Y, Moore PS: Nucleotide sequence of the Kaposi sarcoma-associated herpesvirus (HHV8). Proc Natl Acad Sci USA 1996, 93:14862-14867.

44. Searles RP, Bergquam EP, Axthelm MK, Wong SW: Sequence and genomic analysis of a Rhesus macaque rhadinovirus with similarity to Kaposi's sarcoma-associated herpesvirus/human herpesvirus 8. J Virol 1999, 73:3040-3053.

45. Stamminger T, Honess RW, Young DF, Bodemer W, Blair ED, Fleckenstein B: Organization of terminal reiterations in the virion DNA of herpesvirus saimiri. J Gen Virol 1987, 68(Pt 4):1049-1066.

46. Lagunoff M, Ganem D: The structure and coding organization of the genomic termini of Kaposi's sarcoma-associated herpesvirus. Virology 1997, 236:147-154

47. Albrecht JC, Nicholas J, Biller D, Cameron KR, Biesinger B, Newman C, Wittmann S, Craxton MA, Coleman H, Fleckenstein B, et al: Primary structure of the herpesvirus saimiri genome. J Virol 1992, 66:5047-5058.

48. Tong L, Stow ND: Analysis of herpes simplex virus type 1 DNA packaging signal mutations in the context of the viral genome. J Virol 2010, 84:321-329.

49. Wang JB, McVoy MA: A 128-Base-Pair Sequence Containing the pac1 and a Presumed Cryptic pac2 Sequence Includes cis Elements Sufficient To Mediate Efficient Genome Maturation of Human Cytomegalovirus. J Virol 2011, 85:4432-4439.

50. McVoy MA, Nixon DE, Hur JK, Adler SP: The ends on herpesvirus DNA replicative concatemers contain pac 2 cis cleavage/packaging elements and their formation is controlled by terminal cis sequences. $J$ Virol 2000 74:1587-1592.

\section{doi:10.1186/1743-422X-8-406}

Cite this article as: Palmeira et al:: Sequencing of bovine herpesvirus 4 v.test strain reveals important genome features. Virology Journal 2011 8:406.

\section{Submit your next manuscript to BioMed Central and take full advantage of:}

- Convenient online submission

- Thorough peer review

- No space constraints or color figure charges

- Immediate publication on acceptance

- Inclusion in PubMed, CAS, Scopus and Google Scholar

- Research which is freely available for redistribution

Submit your manuscript at www.biomedcentral.com/submit
Biomed Central 